\title{
Four cases of production-installation simulation for free-form concrete panels
}

\author{
Jeeyoung Lim ${ }^{1}$, Liu Yue ${ }^{2}$, Youngju $\mathrm{Na}^{3,}{ }^{*}$, Sunkuk Kim ${ }^{4}$ \\ 1, 2, 3, 4 Department of Architectural Engineering, Kyung Hee University, Republic of Korea
}

\author{
Index Terms \\ FCP (Free-form Concrete \\ Panels) \\ Schedule Estimation \\ Simulation Model \\ Production-Installation \\ PCM (Phase Change Material)
}

Received: 19 October 2014

Accepted: 20 July 2015

Published: 22 February 2016

\begin{abstract}
The demand for free-form buildings has increased. Yet, it has several issues, including the increased cost and duration and decreased constructability, owing to difficulties in producing and installing members of the building surface. To solve these problems, a technology to produce FCP using a CNC machine was developed. The technology delivers the free-form building information to the CNC machine and creates PCM shapes by delivering information. Such PCM acts as a mold to produce FCP. The efficiency of FCP production installation is critical in applying this technology since the construction site, duration, and project costs are limited. Thus, the purpose of this study is on four cases of production-installation simulation for Free-Form Concrete Panels. The factors that influence FCP production installation are analyzed, and four simulation models are proposed using the equation to estimate the time required for FCP production installation. The factor that has the biggest influence on FCP production-installation can be identified through simulations, which is likely to reduce the construction duration when the technology is adopted on-site. Further simulations considering the construction duration and cost and quality are needed, and such should be verified through technology application on-site.
\end{abstract}

(C) 2016 TAF Publishing. All rights reserved.

\section{INTRODUCTION}

The demand for free-form buildings has increased, yet there are several problems, including the increased cost and construction duration and decreased constructability at the construction phase upon building free-form structures and buildings [1], [2], [3] and [4]. To solve these problems, a technology to produce FCP using a CNC (Computerized Numeric Control) machine is developed. The technology is delivering the free-form building information to the CNC machine and creating PCM shapes by the delivered information. Such PCM acts as a mold to

\footnotetext{
*Corresponding author: Sunkuk Kim
}

E-mail:kimskuk@khu.ac.kr produce FCP [5], [6], [7], [8]. Efficiency of FCP productioninstallation is critical in applying this technology since the

construction site, duration and project costs are limited [9]. Since the construction schedule is directly linked to the cost, unnecessary processes in producing FCP should be eliminated and $\mathrm{CP}($ Critical Path) should be minimized to reduce the duration. Thus, the purpose of this study is on four cases of production-installation simulation for FreeForm Concrete Panels.

\section{PRELIMINARY STUDY}

Studies related to free-form concrete production technologies include the study conducted by [10] and Lindsey and Digital [11], in which a CNC machine is used to 
produce EPS-formwork [10]-[11], and [12] used digital molds created by the CNC machine and acryl glass to produce free-form concrete [12]. [13] used wood to produce molds with a CNC machine and proceeded with a study on the technology to produce free-form concrete members [13]. CRAFT(2013) studied the construction process, robot automation, new materials and computer design for automation of free-form concrete pouring, as well as conducted a study on machine development and application for construction automation [14]. [15] researched on 3D printing to produce free-form concrete members. However, the studies mentioned above merely introduce the production of free-form concrete, not considering the construction duration and constructability. Therefore, a study to estimate the production-installation time for efficient application of FCP produced under the limited site conditions is required [15].
For FCP production, firstly, there is a free-form building design, FCP data are extracted, a form is manufactured using a CNC machine, and then FCP is produced and installed [5]-[6]-[9]- [8].

Prior to conducting a study on estimating the duration, the influence factors on FCP production-installation in consideration of the process efficiency are as analyzed in Figure 1. Taking into account of the FCP productioninstallation process for analyses of influence factors, the steps are divided into PCM mold production, FCP production and FCP installation. The influence factors significant in determining the $\mathrm{CP}$ of FCP productioninstallation include the number of CNC machines, PCM cooling time, FCP pouring method, FCP curing and the number of crews ( 1 crane and the number of workers for FCP installation). This is shown in Fig. 1.
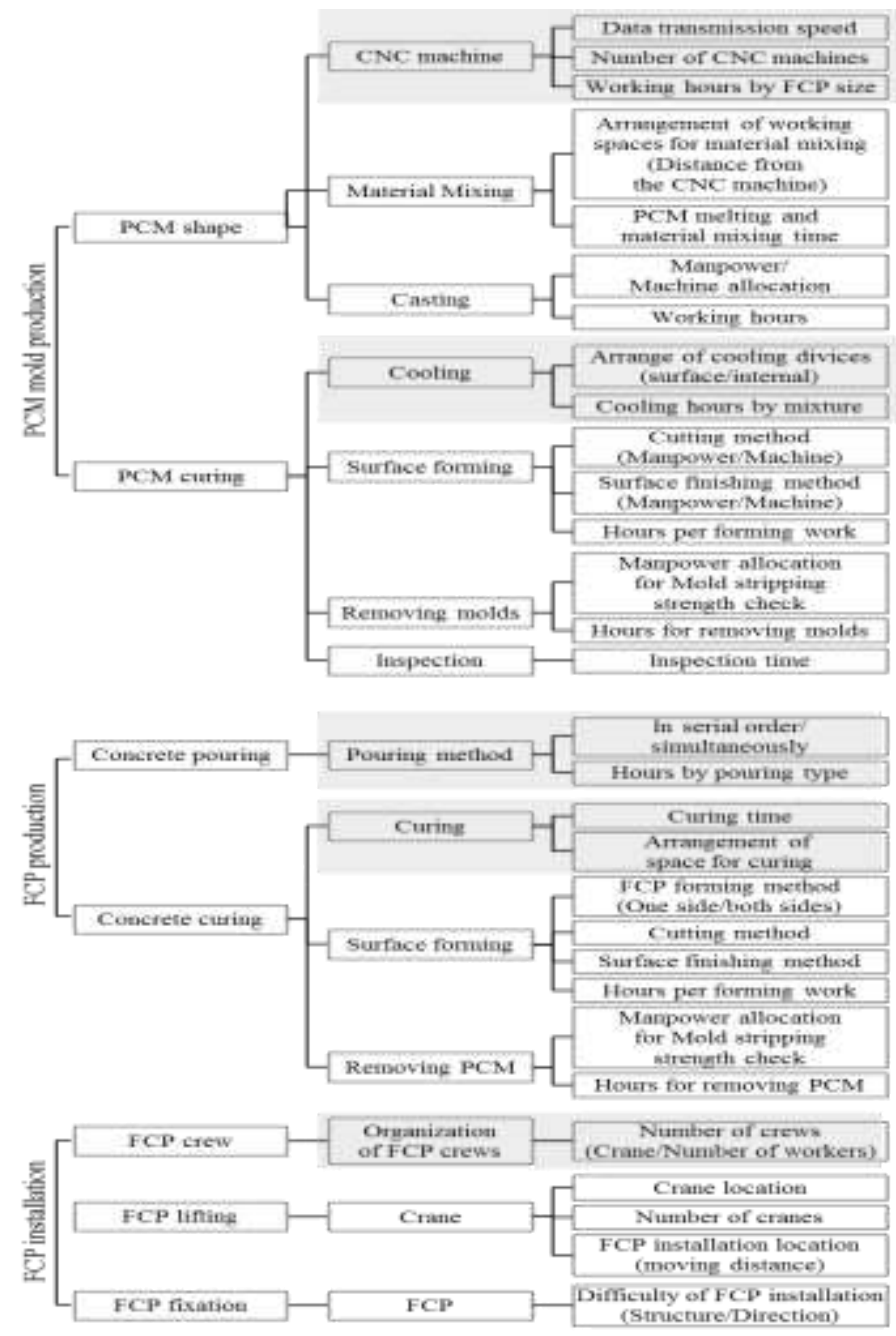

Fig. 1. Analysis of influence factors for FCP production-installation

\section{PRODUCTION-INSTALLATION SIMULATION OF FCP}

As shown in Table 1, the process of FCP production- 
installation is divided into PCM production by CNC Machine, PCM Finishing, Concrete Casting, FCP Curing and FCP Installing. CP is determined by the time required for installation and curing. Fig. 2 represents the case in which the installation time is $\mathrm{CP}$ and Fig. 3 where the curing time is CP. CP is determined by the time required for installation and curing. Fig. 2 represents the case in which the installation time is $\mathrm{CP}$ and Fig. 3 where the curing time is $\mathrm{CP}$.

TABLE 1.

PROCESS OF SCHEDULE ESTIMATION [5]

\begin{tabular}{lcrl}
\hline \hline $\begin{array}{c}\text { Work Type Number } \\
\text { (Ai-j) }\end{array}$ & Work Type & $\begin{array}{c}\text { Schedule Estimation } \\
\text { Required } \\
\text { (ti-j) }\end{array}$ & \multicolumn{1}{c}{ Remark } \\
\hline Ai-1 & PCM production by CNC & 25 & $\cdot \mathrm{n}:$ sequential mold \\
& Machine & \multicolumn{3}{c}{ number } \\
Ai-2 & PCM Finishing & 5 & $\cdot 1$ day=8hr \\
Ai-3 & Concrete Casting & 30 & \\
Ai-4 & FCP Curing & 480 & \\
Ai-5 & FCP Installing & 60 & \\
\hline \hline
\end{tabular}

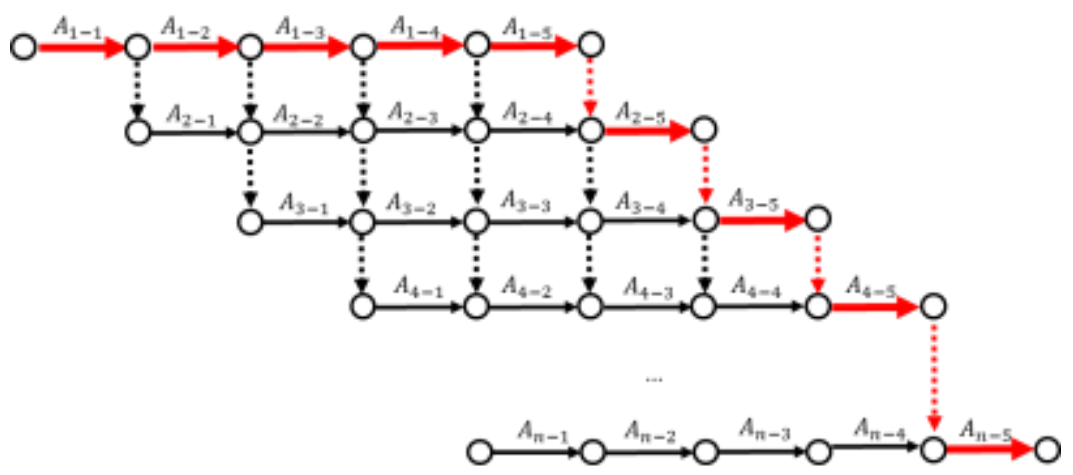

Figure 2. FCP production-installation Plan A.

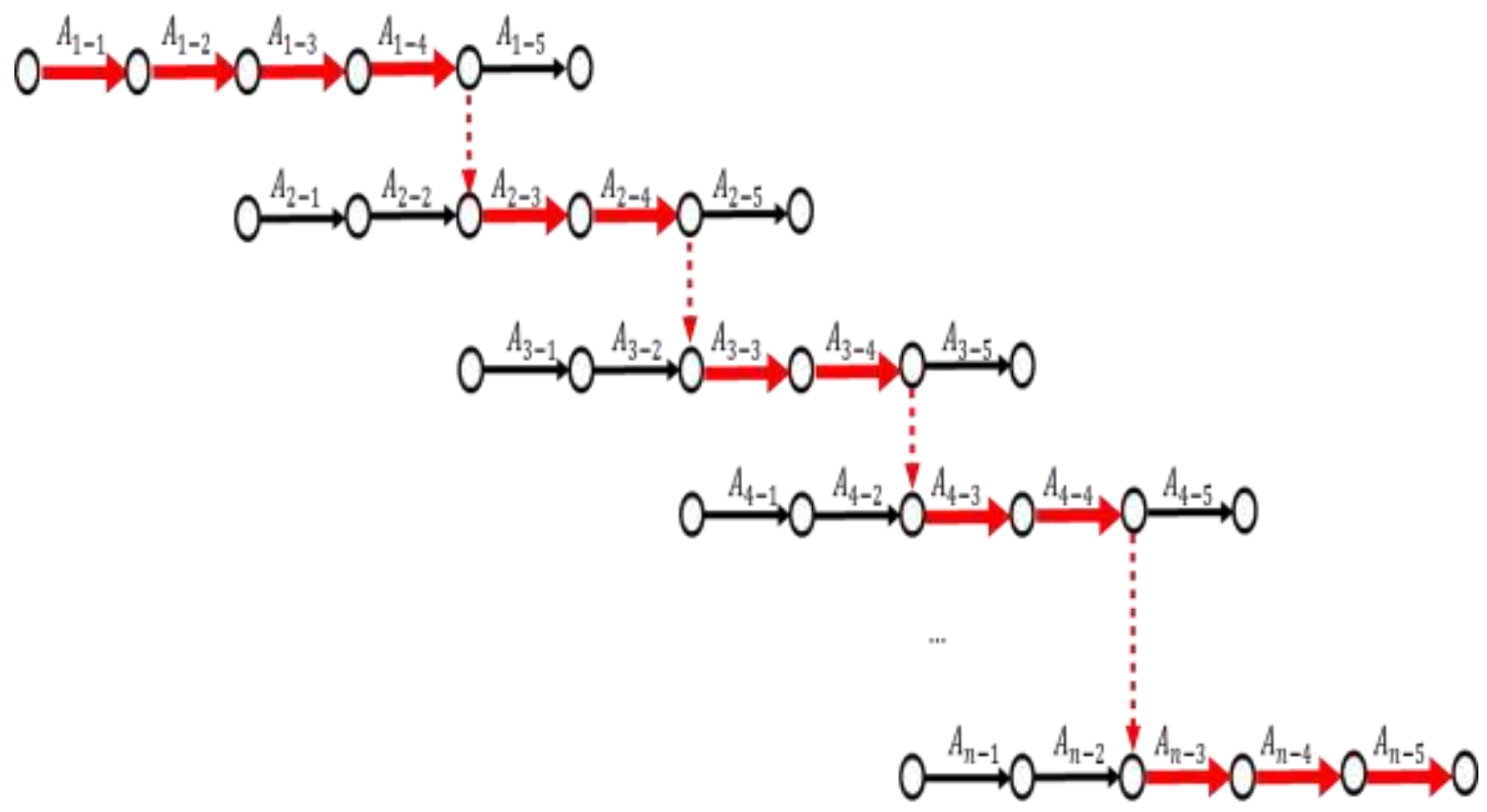

Fig. 3. FCP production-installation Plan B. 

The time required for installation and that for curing are separated as CP is determined by the installation and curing time, and the equation for estimating the time for FCP production-installation is drawn. When the installation time is CP, it is as shown in Equation (1) and when the curing time is $\mathrm{CP}$, it is as in Equation (2).

i) FCP production-installation plan $\mathrm{A}$,

$\mathrm{TFCP}=[\{(\mathrm{ti}-1+\mathrm{ti}-2) \times \mathrm{NCNC}$ work $\}+\mathrm{ti}-3+\mathrm{ti}-4]+(\mathrm{ti}-3+\mathrm{ti}-$

4)

$\times\{$ NFCP-total $/($ NCNC machine $\times$ NCNC work $)\}+$ ti $-5 \times$ (NFCP-remainder/ Ncrew)

$\mathrm{TFCP}=[\{(\mathrm{ti}-1+\mathrm{ti}-2) \times \mathrm{NCNC}$ work $\}+\mathrm{ti}-3+\mathrm{ti}-4]+\mathrm{ti}-5 \times$

$\{($ NFCP-total/Ncrew) (1)

ii) FCP production-installation plan $\mathrm{B}$,

Fig. 4. Cases of

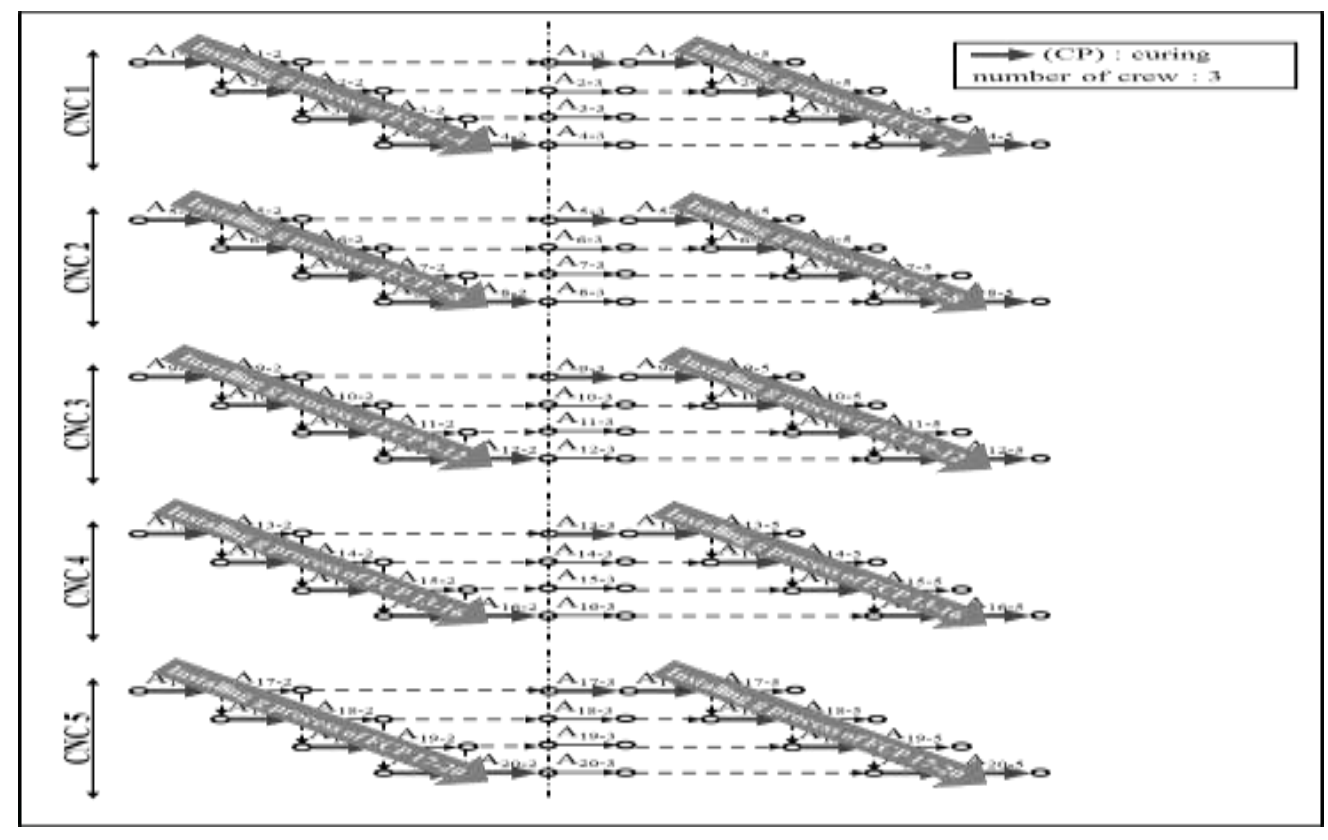

production-installation simulation

FCP

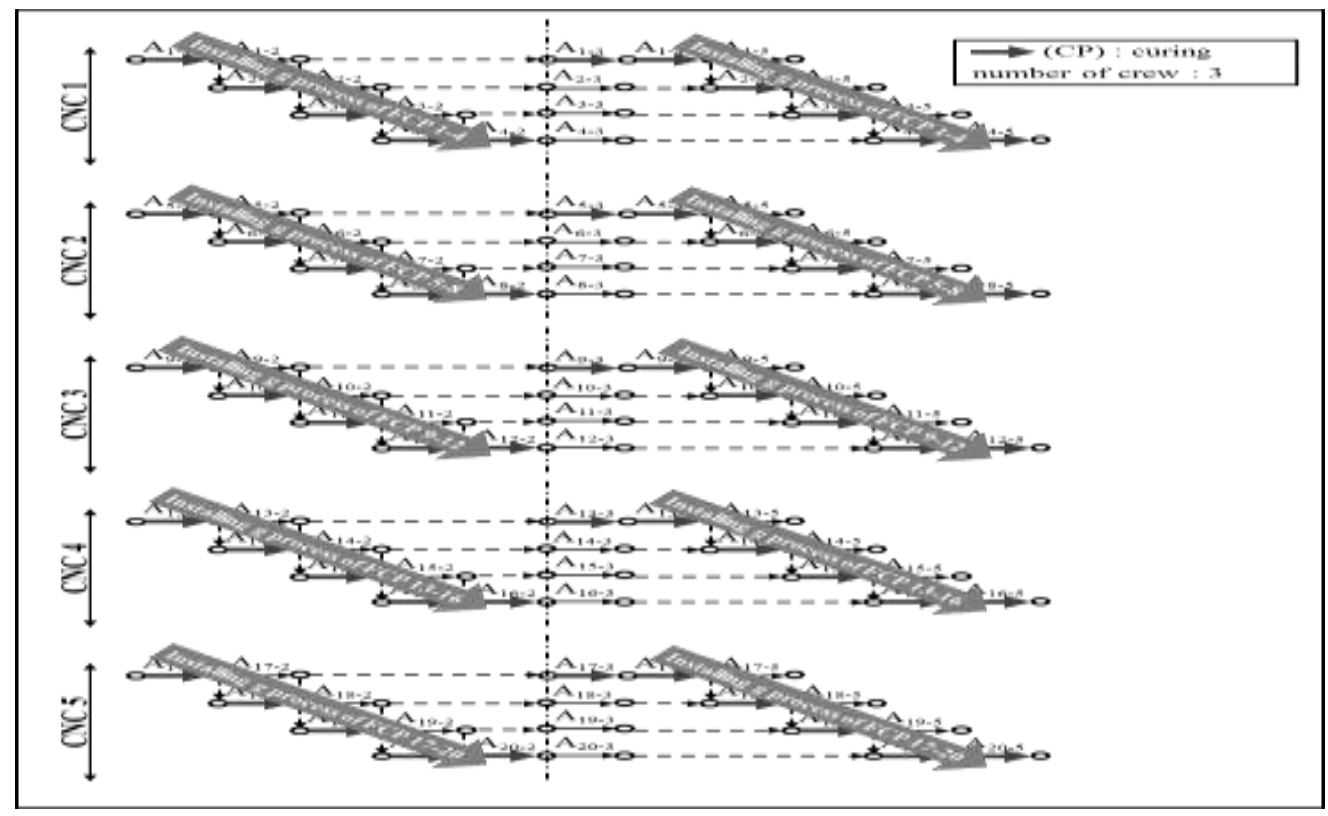

Figure 5. FCP production-installation plan utilizing 5 unit of CNC machine(Case 4) 
Prior to proposing FCP simulation models, several assumptions are made. It is assumed that the quality of

FCP is met without considering the area of all processes. 1 day indicates 8 hours, the total building surface area for producing FCP is $3,000 \mathrm{~m}^{2}, \mathrm{FCP}$ is $2 \times 2 \mathrm{~m}$ in average. Simulation models are presented for 750 members produced by applying simultaneous pouring and taking into account of cost.

4 cases of FCP production-installation schedule estimation simulation are as illustrated in Fig. 4. Case 1 is 2 CNC machines, 3 times of CNC machine work (in other words, 6 FCPs in 1 simultaneous pouring, 125 times of simultaneous pouring), $1 \mathrm{crew}$ and the result of 134 days. Case 2 is 4 CNC machines, 4 times of CNC machine work (in other words, 16 FCPs in 1 simultaneous pouring, 47 times of simultaneous pouring), 1 crew and the result of 52 days. Case 3 is 4 CNC machines, 4 times of CNC machine work (in other words, 16FCPs in 1 simultaneous pouring and 47 times of simultaneous pouring), 4 crews and the result of 51 days. Case 4 is 5 CNC machines, 4 times of CNC machine work (in other words, 20 FCPs in 1 simultaneous pouring, 38 times of simultaneous pouring), 3 crews and the result of 41 days.

As shown in Fig. 5, Case 4 has the shortest duration for FCP production-installation, which is 42 days. CNC 1-5 represent respective processes in which one unit of equipment produces and installs FCP. When compared to the free-form roof work of $\mathrm{Q}$ National Museum (area: $3,000 \mathrm{~m}^{2}$ ), there is a reduced duration of around $58 \%$.

\section{CONCLUSION}

The study identified the influence factors on FCP production-installation using only PCM and conducted simulations to estimate the duration (schedule) to produce 4 different models. Among those models, a prospective model is chosen for in-situ production. The following conclusion was made from this study.

The number of CNC machines and the number of CNC machine work determine the number of FCPs in 1 simultaneous pouring, and the number of FCPs in 1 simultaneous pouring has an effect on the FCP productioninstallation time.

The number of crews impacts the FCP installation time and changes the CP of FCP production-installation. Thus, it is an important influence factor in estimating the schedule.

According to the simulation, the duration for construction reduced around 58\% compared to the freeform roof work of Q National Museum (area: 3,000 m²).

Further studies should consider loading spaces as the construction area is not considered herein. In addition, simulations that take into account of not only the duration, but also cost and quality are needed, and such should be verified on site.

\section{ACKNOWLEDGEMENT}

This work was supported by the National Research Foundation of Korea (NRF) grant funded by the Korea government (MSIP) (No. 2013R1A2A2A01068297).

\section{REFRENCES}

[1] J. Payne, "The Sydney Opera House, Inside and Out," pp. 247-277, 2003.

[2] B. Plaza, "The return on investment of the Guggenheim Museum Bilbao," International Journal of Urban and Regional Research, vol. 30, no. 2, pp. 452-467, 2012.

[3] H. C. Ryu, "Characteristics of digital tectonics of freeform structures designed through digital process," Journal of Korea Design Forum, vol. 25, pp. 225-236, 2009.

[4] Y. Toyota, "Walt disney concert hall opens," Naata Acoustics News, 2003.

[5] D. Lee, "A study of construction and management technology of free-form buildings," Doctoral thesis, Kyung Hee University, Seoul, South Korea, 2015.

[6] K. Kim, K. Son, E. D. Kim and S. Kim, "Current trends and future directions of free-form building technology," Architectural Science Review, vol. 58, no. 3, pp. 230-243, 2014.

[7] K. Kim, "Development of production and management technology of free-form concrete segment," Master's thesis, Kyung Hee University, Seoul, South Korea, 2014.

[8] J. Lim, D. Lee and S. Kim, "Analysis on the factors influencing layout for production-installation work of free-form concrete panels in PCM mold," in Proceeding of the 2015 Spring Annual Conference of the Korea Institute of Building Construction, vol. 15, no. 1, pp. 121-122.

[9] T. Kim, "Flexible mold production process for using the PCM," in Proceeding of the 2014 Spring Annual Conference of the Korea Institute of Building Construction, vol. 14, no. 1, pp. 272-273.

[10] P. Mandl, P. Winter and V. Schmid, "Freeforms in composite constructions-The new house of music and music theatre "mumuth," in Graz," Tagungsb and Eurosteel, 2008.

[11] B. Lindsey and D. Gehry, Material Resistance Digital Construction. Basel, Switzerland: Birkhauser, 2001. 
[12] F. Architeckten and ABB Architeckten 'The Buble, 1999.

[13] I. Toyo, H. Takeo, Y. Leo, S. Zai and H. Takayasu "Meiso no mori crematorium gifu," Toyo Ito and Associates, Kakamigahara, Gifu Prefecture, Japan, 2006.

[14] CRAFT (Center for Rapid Automated Fabrication Technologies) (2014, December). University of
Southern California. [Online]. Available: http://www.craft-usc.com/

[15] IMCRC (Innovative Manufacturing and Construction Research Centre) (2014, December). Loughborough University. [Online]. Available: http://goo.gl/jmT896

\section{— This article does not have any appendix-}

